\title{
Trochlear Nerve Schwannoma with Intratumoral Hemorrhage Presenting with Persistent Hiccups: A Case Report
}

\author{
Ryusuke Hatae $^{1,3}$ Masayuki Miyazono ${ }^{1}$ Ryusuke Kohri ${ }^{1}$ Kazushi Maeda ${ }^{1}$ Shinji Naito ${ }^{2}$
}

${ }^{1}$ Department of Neurosurgery, National Hospital Organization Ureshino Medical Center, Ureshino, Saga, Japan

2 Department of Pathology, National Hospital Organization Ureshino Medical Center, Ureshino, Saga, Japan

${ }^{3}$ Department of Neurosurgery, Graduate School of Medical Sciences, Kyushu University, Fukuoka, Japan

J Neurol Surg Rep 2014;75:e183-e188.

\author{
Address for correspondence Ryusuke Hatae, MD, Department of \\ Neurosurgery, Graduate School of Medical Science, Kyushu University, \\ 3-1-1 Maidashi, Higashi-ku, Fukuoka 812-8582, Japan \\ (e-mail: ryu_0202@hotmail.com).
}

\begin{abstract}
Keywords

- persistent hiccup

- trochlear nerve schwannoma

- intratumoral hemorrhage

Trochlear nerve schwannoma without neurofibromatosis is extremely rare. To our knowledge, only 31 surgical cases have been reported to date, and only 2 cases of trochlear nerve schwannoma with intratumoral hemorrhage have been reported. None of those cases presented with persistent hiccups. We report the case of a 44-year-old man with trochlear nerve schwannoma associated with intratumoral hemorrhage who presented with a 10-day history of persistent hiccups. Computed tomography and magnetic resonance imaging revealed a solid tumor with a 3-cm diameter and intratumoral hemorrhage in the left petroclival region that compressed the midbrain and pons. Subtotal removal of the tumor was performed via the zygomatic transpetrosal approach. Intraoperative findings revealed a tumor arising from the trochlear nerve. The histologic diagnosis was schwannoma of Antoni type A cells with intratumoral hemorrhage. Although the patient's left trochlear nerve palsy worsened temporarily, his postoperative course was uneventful. We present this rare case and discuss the mechanism underlying the patient's persistent hiccups.
\end{abstract}

\section{Introduction}

Schwannomas are tumors originating from Schwann cells and account for $8 \%$ of all primary brain tumors. ${ }^{1}$ Although schwannomas develop mainly in the sensory nerves, most often the vestibular nerve, in very rare cases they can develop in the trochlear nerve, which is a motor nerve. ${ }^{1,2}$ To our knowledge, only 31 cases of trochlear nerve schwannoma have been reported. ${ }^{3-32}$ In many of these cases, the patient initially presented with headache, double vision (associated with trochlear nerve paralysis or oculomotor paralysis), hemiplegia, or cerebellar symptoms; however, none of the patients had an initial presentation of persistent hiccups. Furthermore, a schwannoma complicated by intratumoral hemorrhage is rare, with only 2 of the 31 reported cases of trochlear nerve schwannoma exhibiting this complication. ${ }^{23,31}$

We report a very rare case of trochlear nerve schwannoma with an intratumoral hemorrhage that was the likely trigger of persistent hiccups and was treated with tumor resection.

\section{Case Report}

A 44-year-old man was referred to our hospital because of persistent hiccups lasting for 10 days. The patient did not complain of double vision, although his results for the Bielschowsky head-tilt test were positive, which suggested left trochlear nerve paralysis. There were no signs of disorders received

February 8, 2014

accepted after revision

April 22, 2014

published online

June 4, 2014
DOI http://dx.doi.org/

10.1055/s-0034-1378156. ISSN 2193-6358. (c) 2014 Georg Thieme Verlag KG
Stuttgart · New York

License terms

((1) $\circledast$ 


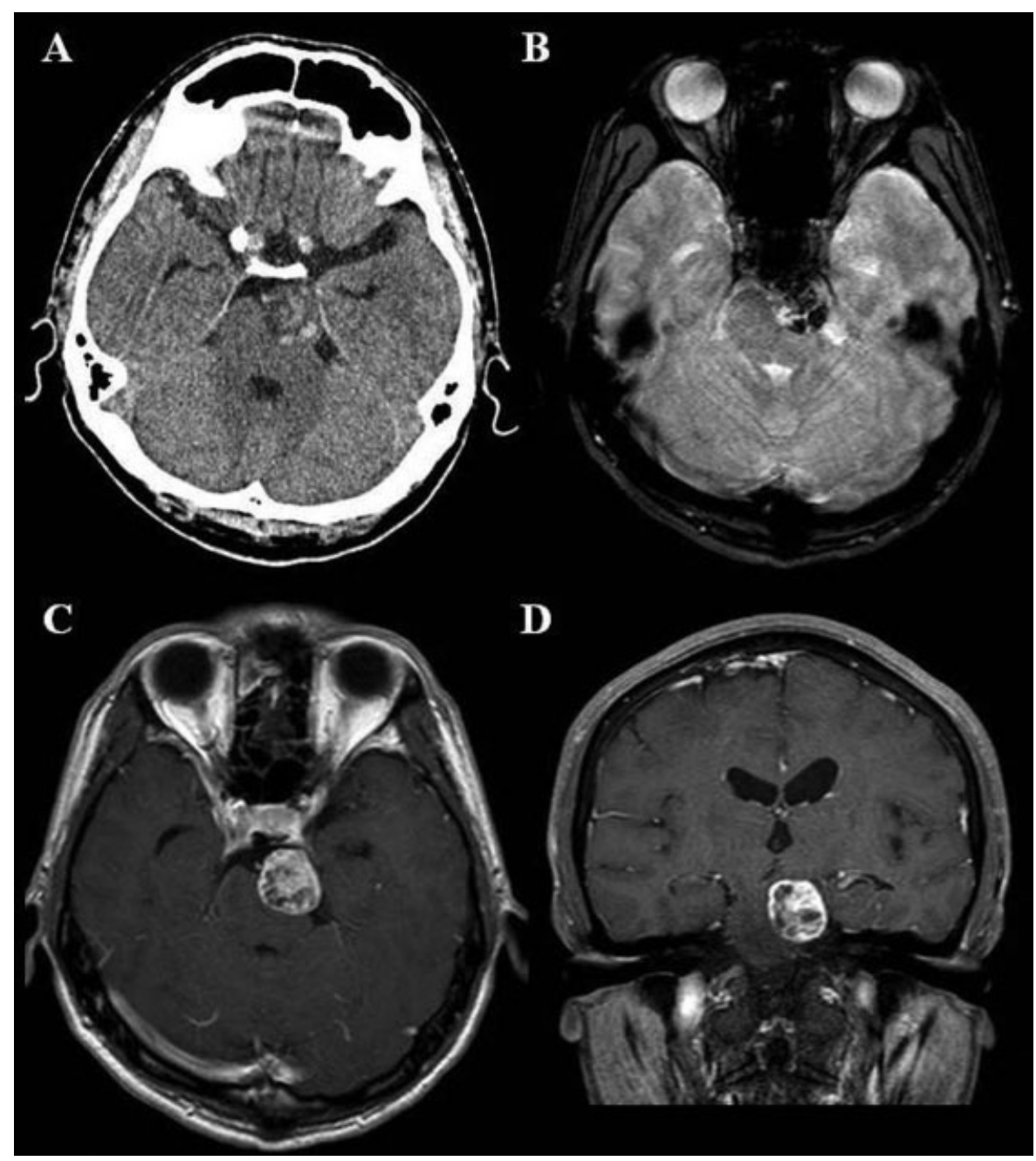

Fig. 1 (A) Computed tomography performed on admission revealing a low-density mass with a high-density area in the interpeduncular and prepontine cistern. (B) T2*-weighted magnetic resonance image (MRI) showing hypointensity in the tumor, suggesting an intratumoral hemorrhage.(C) Axial and (D) coronal T1-weighted gadolinium-enhanced MRIs revealing a well-circumscribed enhancing lesion in the interpeduncular and prepontine cistern, compressing the brainstem.

affecting the cerebral nerves including the oculomotor, trigeminal, and abducens nerves. The patient also showed no signs of hemiplegia, cerebellar symptoms, or headache. The hiccups subsided spontaneously on the day following the patient's first visit to our facility.

Computed tomography (CT) revealed the presence of an isodense tumor, which was partially accompanied by a hyperdense inner region, in the left petroclival area ( - Fig. 1A). Magnetic resonance imaging (MRI) also revealed a well-demarcated tumor $(27 \times 27 \times 30 \mathrm{~mm})$ in the left petroclival area. The tumor had mixed intensity (isointensity to hypointensity) on a T1-weighted image, mixed intensity (isointensity to hyperintensity) on a T2-weighted image, isointensity on a fluid-attenuated inversion-recovery image, and hypointensity (consistent with the highintensity area on the CT scan) on a $\mathrm{T}^{*}$-weighted image (-Fig. 1B). The tumor showed heterogeneous contrast enhancement in the presence of the contrast agent gadolinium (-Fig. 1C, D). Imaging revealed that the tumor compressed the midbrain and pons from the left anterior direction, although there was no significant change of intensity in these regions. A heavy T2-weighted image showed that the tumor was in contact with the left oculomotor nerve in the superior region and with the left trigeminal nerve in the inferolateral region.

Tumor resection was performed using the zygomatic transpetrosal approach (consisting of an anterior transpetrosal approach and a zygomatic arch resection). Although this allowed the tumor to be freed from the trigeminal nerve, the trochlear nerve had become partially assimilated by the tumor membrane, leading to the diagnosis of a trochlear nerve-derived tumor (-Fig. 2A). Because the tumor was partially but strongly attached to the brainstem and clivus, its membrane was incised for internal decompression. A blood clot found inside the tumor, implying intratumoral bleeding, was then removed (-Fig. 2B). The tumor was resected while keeping the tumor membrane close to the brainstem and clivus and while leaving the medial membrane intact. Because a sizable air cell had developed at the petrous bone, we collected fat from the abdominal region, and after 

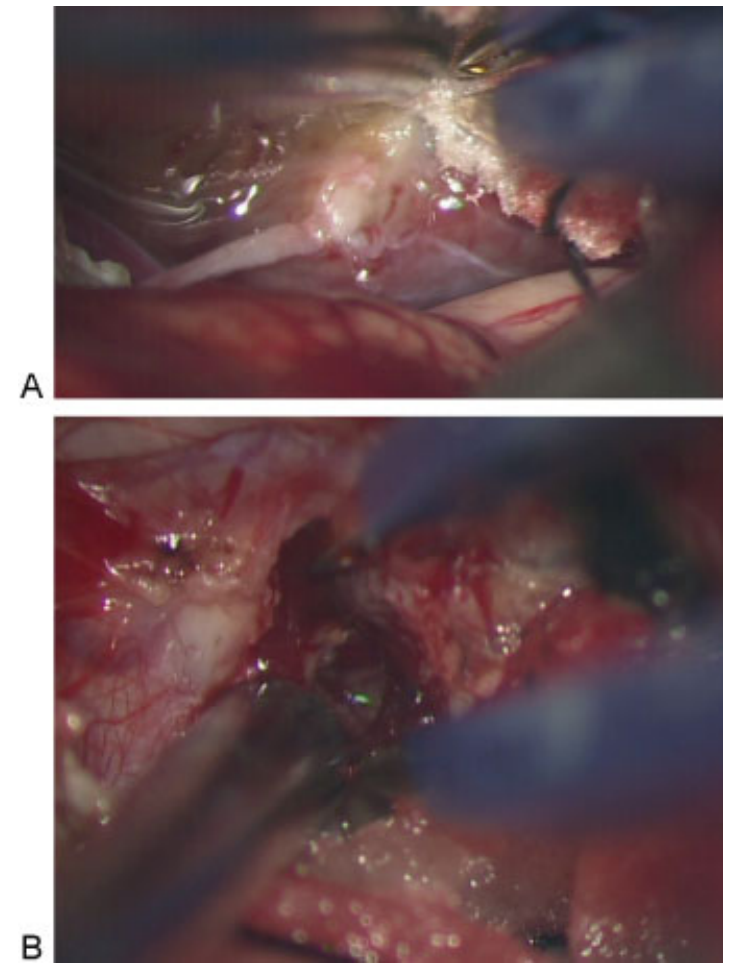

Fig. 2 Intraoperative photographs showing that (A) the tumor originates from the trochlear nerve and (B) there is intratumoral hemorrhage.

bone resection, the defect was filled with fat to complete the operation. Postoperative histopathologic examination revealed entangled and proliferating spindle cells with partially swollen quasi-circular nuclei, which were indicative of a schwannoma composed primarily of Antoni type A cells ( - Fig. 3A). Traces of bleeding accompanied by hyalinized blood vessels and hemosiderin deposition were noted inside the tumor (-Fig. 3A inset), and the removed blood clot contained blood from both recent and previous bleeding (-Fig. 3B).

Postoperative MRI confirmed that the tumor had been removed while keeping only the left membrane intact (-Fig. 4). The patient showed temporary postoperative aggravation of left trochlear nerve paralysis, but no new symptoms appeared. Since then ( 1 year has passed), the symptoms have not recurred. In addition, MRI performed 6 months after the operation showed no change in the size of the residual tumor.

\section{Discussion}

- Table 1 summarizes the 31 surgical cases that have been reported to date, together with the case reported here (3-32). Patients with trochlear nerve schwannoma often present initial symptoms of double vision (60\%), hemiplegia (43\%), headache (40\%), and cerebellar signs (37\%) (-Table 1). Although cases of this tumor presenting with diverse symptoms have been reported, no case with persistent hiccups as the initial symptom was previously described.

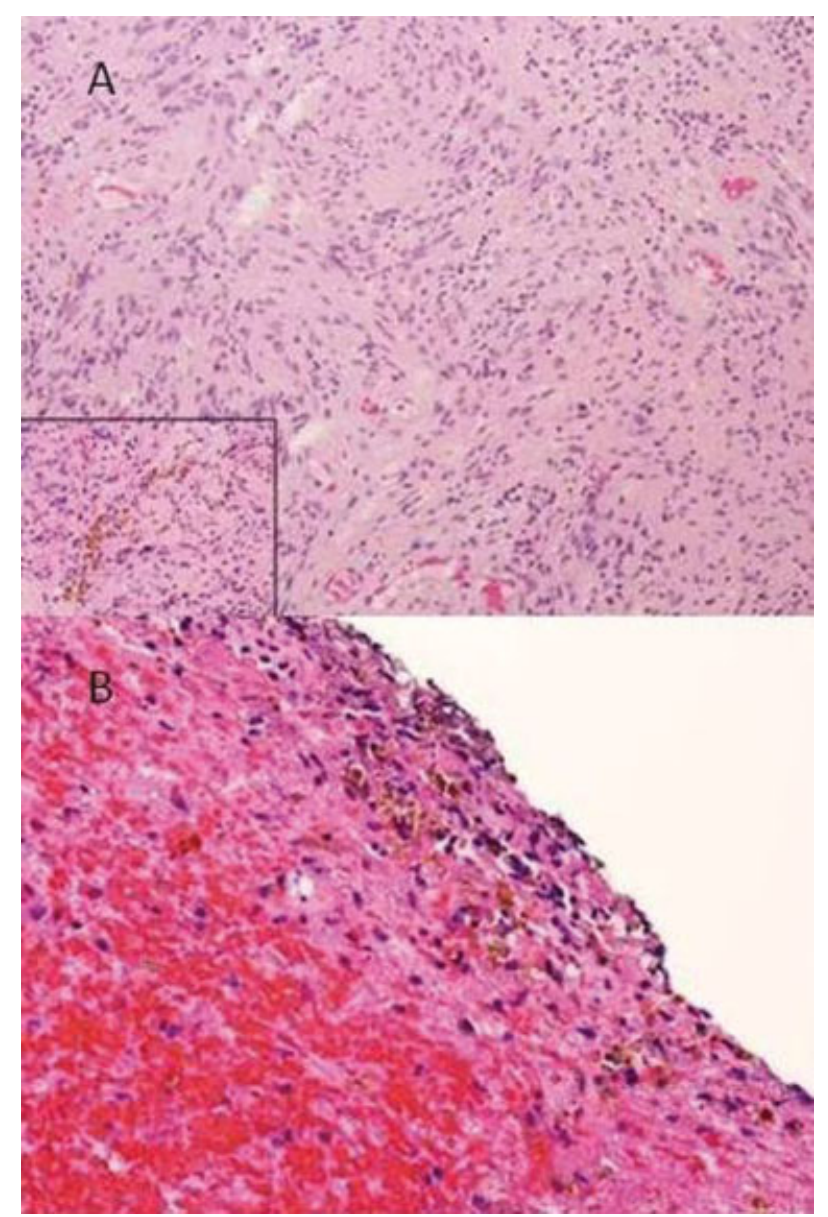

Fig. 3 (A) Photomicrographs showing that the tumor is characterized by closely packed interwoven cells with Verocay bodies. Hematoxylin and eosin: magnification $\times 10$. Some brown hemosiderin deposits are seen in the tumor (inset; magnification $\times 20$ ). (B) Recent and previous hemorrhages are observed in the hematoma. Hematoxylin and eosin: magnification $\times 10$.

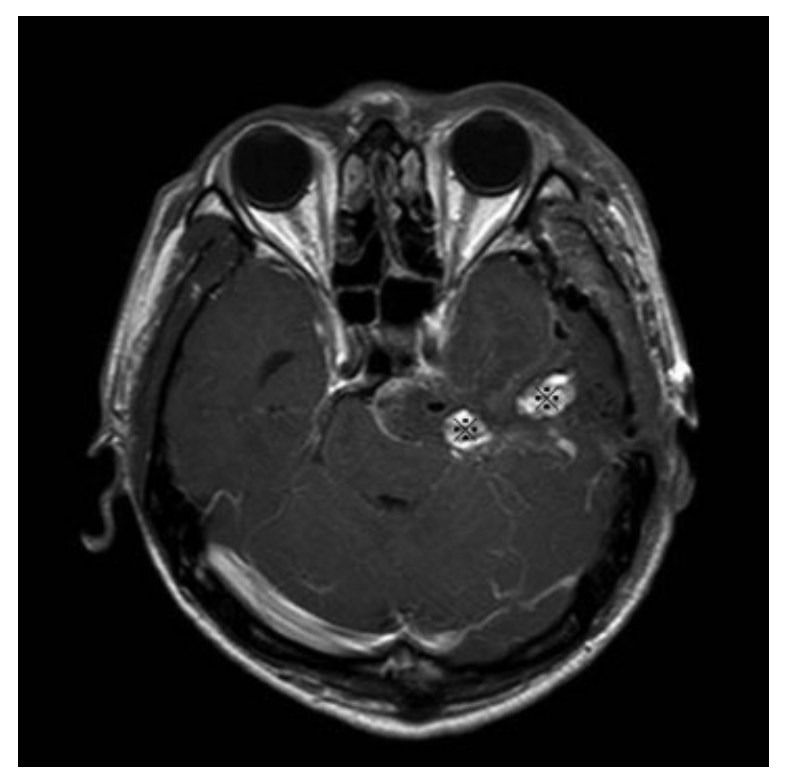

Fig. 4 Postoperative T1-weighted gadolinium-enhanced magnetic resonance imaging revealing subtotal removal of the tumor. Adipose tissue $(x)$ to cover is also present. 
Table 1 Summary of 32 surgical cases of trochlear neurinoma ${ }^{3-32}$ including our case

\begin{tabular}{|c|c|}
\hline \multicolumn{2}{|l|}{ Patients } \\
\hline Age (yrs) & $48.5 \pm 14.9(16-68)$ \\
\hline Sex (male:female) & $13: 17$ \\
\hline \multicolumn{2}{|l|}{ Tumor } \\
\hline Size $(\mathrm{mm})$ & $30 \pm 7(2-54)$ \\
\hline \multicolumn{2}{|l|}{ Symptoms } \\
\hline Headache & $12(40 \%)$ \\
\hline Diplopia & $18(60 \%)$ \\
\hline 3rd cranial nerve disorder & $9(30 \%)$ \\
\hline 4th cranial nerve disorder & $14(47 \%)$ \\
\hline 5th cranial nerve disorder & $8(27 \%)$ \\
\hline 7th cranial nerve disorder & 7 (23\%) \\
\hline 8th cranial nerve disorder & $2(7 \%)$ \\
\hline Long tract sign (motor) & $13(43 \%)$ \\
\hline Long tract sign(sensory) & $3(20 \%)$ \\
\hline Cerebellar sign & $11(37 \%)$ \\
\hline \multicolumn{2}{|l|}{ Duration } \\
\hline Duration of symptoms (months) & $5.5 \pm 16.8(0.3-60)$ \\
\hline \multicolumn{2}{|l|}{ Residual symptoms } \\
\hline 4th nerve palsy & $25(83 \%)$ \\
\hline Others & $6(20 \%)$ \\
\hline
\end{tabular}

Hiccups usually subside within a short time; those lasting $\geq 48$ hours are defined as persistent hiccups, whereas those lasting $\geq 1$ month are termed intractable hiccups. ${ }^{33}$ Gastric flatulence is generally responsible for hiccups, but persistent or intractable hiccups suggest a possible complication by an organic disease. Although the exact mechanism of hiccupping remains unclear, the hiccup reflex arc is known to be composed of several neural pathways. ${ }^{34}$ The afferent pathway involves the sensory fibers of the vagus nerve, the glossopharyngeal branch of the glossopharyngeal nerve, the pharyngeal plexus (C2-C4), and the sympathetic nerves (T6-T12). Its efferent pathway involves the glottis and phrenic nerve, which is linked to the auxiliary respiratory muscles. Linkage to the central nervous system has not been elucidated in detail, but possible interactions with the medulla oblongata (including the solitary nucleus and ambiguous nucleus), part of the pons, reticular formation of the brainstem, phrenic nerve nuclei, and hypothalamus have been suggested. ${ }^{35}$

Causes of persistent or intractable hiccups originating in the central nervous system include vascular, infectious, and structural processes, which are thought to suppress the hiccup reflex. ${ }^{36-38}$ Furthermore, some case reports have attributed hiccups to brainstem lesions, particularly those in the medulla oblongata. ${ }^{36}$ In the present case, although persistent hiccups were observed as the initial symptom, after which they spontaneously subsided, the medulla oblongata had not been directly compressed by the tumor. This finding, together with the observation of brainstem compression by the tumor, suggests that the hiccups in this case may have been caused by intratumoral hemorrhage.

Schwannomas are only rarely complicated by intratumoral hemorrhage. ${ }^{39}$ Historically, clinically significant intratumoral hemorrhage was reported in only a small fraction of vestibular schwannomas. However, advances in imaging and larger analyses suggest that intratumoral hemorrhage is far more common than previously believed and might represent an aspect of the natural history of vestibular schwannomas. ${ }^{39}$ Hemorrhagic vestibular schwannomas often manifest with acute symptom onset and have been studied inadequately since McCoyd's initial description. ${ }^{40-42}$ of the 31 reported cases of trochlear nerve schwannoma, only 2 had intratumoral hemorrhage, and both these cases ${ }^{23,31}$ showed acute aggravation of symptoms (- Table 2). According to a report published by Yamamoto et al, the initial symptoms of this condition include sudden headache, nausea, vomiting, and double vision. ${ }^{31}$ Ohba et al reported a case in which intratumoral hemorrhage occurred during the follow-up of a trochlear nerve schwannoma. Their case showed aggravation of the original symptoms (left hemiparesis, right trochlear nerve paralysis, and sensory disorder of the third branch region of the right trigeminal nerve), as well as developed right oculomotor paralysis and right facial palsy. ${ }^{23}$

Table 2 Summary of three surgical cases of trochlear neurinoma with intratumoral hemorrhage

\begin{tabular}{|l|l|l|l|l|l|l|}
\hline Study & Age, y/Sex & Symptoms & $\begin{array}{l}\text { Duration of } \\
\text { symptoms }\end{array}$ & Size, mm & $\begin{array}{l}\text { Residual } \\
\text { symptom }\end{array}$ & Follow-up \\
\hline Yamamoto et al $^{31}$ & $37 / \mathrm{F}$ & $\begin{array}{l}\text { Sudden onset of } \\
\text { headache, nausea, } \\
\text { vomiting, diplopia }\end{array}$ & $2 \mathrm{wk}$ & $10 \times 9 \times 7$ & Right fourth palsy & $5 \mathrm{y}$ \\
\hline Ohba et al & 23 & $\begin{array}{l}\text { Diplopia, left hemi- } \\
\text { paresis, hypesthesia } \\
\text { of the right face, } \\
\text { right facial palsy, } \\
\text { right third palsy }\end{array}$ & $3 \mathrm{wk}$ & 25 & Right fourth palsy & 4 mo \\
\hline $\begin{array}{l}\text { Hatae et al } \\
\text { (current study) }\end{array}$ & $44 / \mathrm{M}$ & $\begin{array}{l}\text { Persistent hiccup, } \\
\text { left fourth palsy }\end{array}$ & $10 \mathrm{~d}$ & $27 \times 27 \times 30$ & Left fourth palsy & $1 \mathrm{y}$ \\
\hline
\end{tabular}


In the present case, intratumoral hemorrhage was confirmed by intraoperative and pathologic findings. CT performed during the first examination revealed interposition of hyperintense areas within the tumor, and an MRI of the same region revealed low signal intensity on $\mathrm{T}_{2}^{*}$-weighted image. CT performed 2 weeks later revealed the presence of isointensity. These findings suggest that the patient had developed intratumoral bleeding several days before the first visit. In view of the patient's disease history, the hiccups probably began immediately after intratumoral bleeding, suggesting that this may have been their cause. The area affected by the hematoma was located caudal to the tumor. Considering that the tumor was in contact with the tent in the upper direction, and with the clivus in the anterior direction, it is likely that the intratumoral hemorrhage increased the tumor size, probably generating a force that caused downward compression of the pons. This, in turn, may have indirectly stimulated the ambiguous nucleus and solitary nucleus, leading to the onset of persistent hiccups. The lack of hiccups prior to intratumoral hemorrhage, as well as following surgery, supports this hypothesis. The spontaneous disappearance of the hiccups also indicates the involvement of indirect, rather than direct, stimulation.

\section{Conclusions}

We reported a case of trochlear nerve schwannoma in which intratumoral hemorrhage probably caused persistent hiccups. To our knowledge, this is only the third reported case of trochlear nerve schwannoma complicated by intratumoral hemorrhage, and the first case exhibiting persistent hiccups as the initial symptom.

\section{Conflict of Interest}

The authors have no personal financial or institutional interest in any of the drugs, materials, or devices in the article.

\section{References}

1 Russell DS, Rubinstein LJ. Pathology of Tumors of the Nervous System. 5th ed. Baltimore, MD: Williams and Wilkins; 1989: 537-560

2 Ho KL. Schwannoma of the trochlear nerve. Case report. J Neurosurg 1981;55(1):132-135

3 Abe T, Iwata T, Shimazu M, et al. Two cases of trochlear nerve neurinoma. [in Japanese].No Shinkei Geka 1994;22(4):371-375

4 Abe T, Iwata T, Shimazu M, Matsumoto K. Trochlear nerve neurinoma associated with a giant thrombosed dissecting aneurysm of the contralateral vertebral artery. Surg Neurol 1994;42(5): 438-441

5 Bartalena T, Leoni C, Trossello MP, et al. Hourglass cystic schwannoma of the trochlear nerve. Acta Biomed 2010;81(2):147-150

6 Beppu T, Yoshida Y, Wada T, et al. Trochlear and abducens nerve neurinomas accompanied by a cerebellopontine angle meningioma-case report. Neurol Med Chir (Tokyo) 1997;37(5):416-421

7 Boggan JE, Rosenblum ML, Wilson CB. Neurilemmoma of the fourth cranial nerve. Case report. J Neurosurg 1979;50(4): 519-521
8 Celli P, Ferrante L, Acqui M, Mastronardi L, Fortuna A, Palma L. Neurinoma of the third, fourth, and sixth cranial nerves: a survey and report of a new fourth nerve case. Surg Neurol 1992;38(3): 216-224

9 Dolenc VV, Coscia S. Cystic trochlear nerve neurinoma. Br J Neurosurg 1996;10(6):593-597

10 Du R, Dhoot J, McDermott MW, Gupta N. Cystic schwannoma of the anterior tentorial hiatus. Case report and review of the literature. Pediatr Neurosurg 2003;38(4):167-173

11 Garen PD, Harper CG, Teo C, Johnston IH. Cystic schwannoma of the trochlear nerve mimicking a brain-stem tumor. Case report. J Neurosurg 1987;67(6):928-930

12 Gerganov V, Amir S, Koerbel A, Brandes A, Stan A, Madjid S. Cystic trochlear nerve schwannoma. Case report. Surg Neurol 2007; 68(2):221-225

13 Grigorian IuA, Korobova AN. Neurinomas of the trochlear nerve. [in Russian].Vopr Neirokhir 2008;1(1):50-52

14 Jackowski A, Weiner G, O'Reilly G. Trochlear nerve schwannomas: a case report and literature review. Br J Neurosurg 1994;8(2): 219-223

15 King JS. Trochlear nerve sheath tumor; case report. J Neurosurg 1976;44(2):245-247

16 Kohama M, Murakami K, Endo T, Watanabe M, Tominaga T. Surgical and histological observations of trochlear neurinoma: case report. Neurol Med Chir (Tokyo) 2009;49(5):217-220

17 Lanotte M, Giordana MT, Forni C, Pagni CA. Schwannoma of the cavernous sinus. Case report and review of the literature. J Neurosurg Sci 1992;36(4):233-238

18 Leunda G, Vaquero J, Cabezudo J, Garcia-Uria J, Bravo G. Schwannoma of the oculomotor nerves. Report of four cases. J Neurosurg 1982;57(4):563-565

19 Matsui T, Morikawa E, Morimoto T, Asano T. Presigmoid transpetrosal approach for the treatment of a large trochlear nerve schwannoma-case report. Neurol Med Chir (Tokyo) 2002;42(1): 31-35

20 Maurice-Williams RS. Isolated schwannoma of the fourth cranial nerve: case report. J Neurol Neurosurg Psychiatry 1989;52(12): 1442-1443

21 Murakawa T, Sakai H, Ueda T, Yokoyama K, Takada M, Yamada H. Trochlear neurinoma: case report. [in Japanese].Takayama Red Cross Hosp Kiyou 1988;12:163-167

22 Nadkarni TD, Goel A. Trochlear nerve neurinoma presenting as pathological laughter. Br J Neurosurg 1999;13(2):212-213

23 Ohba S, Miwa T, Kawase T. Trochlear nerve schwannoma with intratumoral hemorrhage: case report. Neurosurgery 2006;58(4): E791; discussion E791

24 Samii M, Draf W. Surgery of the Skull Base: An Interdisciplinary Approach. Berlin, Germany: Springer-Verlag; 1989:335-337

25 Santoreneos S, Hanieh A, Jorgensen RE. Trochlear nerve schwannomas occurring in patients without neurofibromatosis: case report and review of the literature. Neurosurgery 1997;41(1): 282-287

26 Shenouda EF, Ghosh A, Coakham HB. Trochlear nerve schwannoma removed by combined petrosal approach. Br J Neurosurg 2002; 16(6):600-604

27 Shenoy SN, Raja A. Cystic trochlear nerve neurinoma mimicking intrinsic brainstem tumour. $\mathrm{Br}$ J Neurosurg 2004;18(2): 183-186

28 Tokuriki Y, Yamashita J, Kikuchi H, Asato R, Handa H. Trochlear nerve neurinoma-case report. Neurol Med Chir (Tokyo) 1988; 28(1):70-73

29 Türe U, Ozduman K, Elmaci I, Pamir MN. Infratentorial lateral supracerebellar approach for trochlear nerve schwannoma. J Clin Neurosci 2002;9(5):595-598

30 Veshchev I, Spektor S. Trochlear nerve neuroma manifested with intractable atypical facial pain: case report. Neurosurgery 2002; 50(4):889-891; discussion 891-892 
31 Yamamoto M, Jimbo M, Ide M, Kubo O. Trochlear neurinoma. Surg Neurol 1987;28(4):287-290

32 Younes WM, Hermann EJ, Krauss JK. Cisternal trochlear nerve schwannoma: improvement of diplopia after subtotal tumour excision. Br J Neurosurg 2012;26(1):107-109

33 Kolodzik PW, Eilers MA. Hiccups (singultus): review and approach to management. Ann Emerg Med 1991;20(5):565-573

34 Samuels L. Hiccup; a ten year review of anatomy, etiology, and treatment. Can Med Assoc J 1952;67(4):315-322

35 Kobayashi Z, Tsuchiya K, Uchihara T, et al. Intractable hiccup caused by medulla oblongata lesions: a study of an autopsy patient with possible neuromyelitis optica. J Neurol Sci 2009;285(1-2): 241-245

36 Nagayama T, Kaji M, Hirano H, Niiro M, Kuratsu J. Intractable hiccups as a presenting symptom of cerebellar hemangioblastoma. Case report. J Neurosurg 2004;100(6):1107-1110
37 Park MH, Kim BJ, Koh SB, Park MK, Park KW, Lee DH. Lesional location of lateral medullary infarction presenting hiccups (singultus). J Neurol Neurosurg Psychiatry 2005;76(1):95-98

38 Witter F, Dipietro J, Costigan K, Nelson P. The relationship between hiccups and heart rate in the fetus. J Matern Fetal Neonatal Med 2007;20(4):289-292

39 Niknafs YS, Wang AC, Than KD, Etame AB, Thompson BG, Sullivan SE. Hemorrhagic vestibular schwannoma: review of the literature. World Neurosurg 2013;13:00379-3

40 Brady AP, Stack JP. Case report: magnetic resonance demonstration of haemorrhagic acoustic neuroma. Clin Radiol 1994;49(1):61-63

41 Lee JP, Wang AD. Acoustic neurinoma presenting as intratumoral bleeding. Neurosurgery 1989;24(5):764-768

42 Propp JM, McCarthy BJ, Davis FG, Preston-Martin S. Descriptive epidemiology of vestibular schwannomas. Neuro-oncol 2006; 8(1):1-11 